\title{
THE EFFECT OF ATROPINE UPON THE OUTPUT OF THE HEARTS OF NORMAL MEN
}

\author{
By W. CARTER SMITH, C. SIDNEY BURWELL, AND MICHAEL J. DEVITO \\ (From the Medical Clinic, Vanderbilt University Hospital)
}

(Received for publication July 25, 1928)

\section{INTRODUCTION}

The output of the heart per minute may be altered by changes in the pulse rate or the output per beat or both. One opinion has it that the output per beat is a relatively fixed amount, another that it may vary within wide limits. The recent observations of Field and Bock (1) upon the effect of posture on the output of the heart indicate that wide variations may occur in the output per beat of the hearts of healthy men. These observations emphasize the importance of the peripheral circulation in influencing the amount of blood brought to the heart and thus influencing its output. The administration of atropine, which increases the heart rate without a proportional effect upon the oxygen consumption of the body, offers a means of studying the question further.

Marshall (2) measured the cardiac output of dogs before and after the administration of atropine and found that the cardiac output remained unchanged in spite of an increase in the heart rate to twice its original value. Similar effects were observed by Harrison, Blalock, Pilcher and Wilson (3) after atropine or vagotomy in dogs. No direct observations of the effect of atropine on the cardiac output of man are recorded. Stewart (4), however, observed the effects of atropine upon the composition of the arterial and venous blood of patients with cardiac disease and found that in certain types of cases an increase in the oxygen saturation of the blood of the arm vein pointed to an increase in the cardiac output. In only one case was this of the same order as the increase in heart rate. In other types of cases the saturation of arm vein blood suggested an unchanged or slightly decreased cardiac output per minute. 
The relations between systemic blood pressure and the cardiac output, per minute and per beat is of interest and the administration of atropine affords an opportunity to study these relations also. The effect of atropine on systemic blood pressure has been studied by Harris (5) in normal adults and by Sturgis, Wearn and Tompkins (6) in patients with "effort syndrome." Harris observed that the subcutaneous injection of $1.2 \mathrm{mgm}$. of atropine was followed by a fall in systolic pressure and a decrease in the pulse pressure. He inferred that the output of the heart was diminished. A similar decrease after a similar dose was found by Sturgis, Wearn and Tompkins (6) in patients with effort syndrome.

Many studies have been made of the effect of atropine on the heart rate. It is important to note that doses of different magnitude may have opposite effects on the heart rate. As pointed out by McGuigan (7) small doses ( 0.4 to $0.6 \mathrm{mgm}$.) may decrease the rate or leave it unchanged while a dose of $1.2 \mathrm{mgm}$. usually suffices to increase it considerably.

\section{METHODS}

Observations on the cardiac output, heart rate, metabolic rate, and systemic blood pressure were made before and after the intravenous injection of $1.2 \mathrm{mgm}$. of atropine sulphate. In a preliminary experiment $2.4 \mathrm{mgm}$. were injected but this amount rendered the subject so restless and uncomfortable that the observations were not comparable with those made before the injection when the subject was quiet and at ease.

The output of the heart was measured by the method of Field, Bock, Gildea and Lathrop (8). All observations were made in the morning with the subject having had no food for at least 12 hours and after he had rested 30 to 45 minutes in the reclining position, in which he remained while the observations were made. Each subject was trained in the necessary respiratory manoeuvers before the cardiac output was actually measured. Then a preliminary measurement was made and if the subject showed himself well trained the complete experiment was carried out on the following day. The order of procedure was as follows: first the samples of alveolar and "mixed venous" gases were collected, then the expired air was collected for a six minute period, and finally the blood pressure was taken. At short intervals during these observations the pulse was counted. These counts were averaged and the result is designated the "average pulse rate."

When this control observation was completed $1.2 \mathrm{mgm}$. of atropine sulphate were given intravenously and the observations immediately repeated, with the addition of several measurements of the blood pressure during the procedure.

A third series of observations was made 1 to $1 \frac{1}{2}$ hours after injection of atropine. 
In one case (subject C. B.) a fourth measurement was made three hours after the injection of atropine. In case 3 (subject T. A.) an error occurred in the control observation on April 1. The study of this subject's cardiac output was repeated therefore 10 days later.

The subjects were healthy young men, medical students or members of the staff of the Vanderbilt University Hospital. Their ages were from 22 to 29 years.

Errors may have resulted from the restlessness attendant upon remaining quiet for a long time in subjects who disliked prolonged inactivity or from a progressive reduction in metabolic rate and cardiac output in subjects of a different type. To minimize the possibility of these errors the subjects were permitted to get up, walk about, and drink a little water after the second series of observations. They then returned to the reclining chair and rested 30 to 40 minutes before the final series of observations. After the injection of atropine all subjects complained of dryness of the mouth, several of slight difficulty in accommodation, and some of slight dizziness on arising from the reclining chair. These minor discomforts may have introduced slight errors also.

\section{RESULTS}

The effect of atropine upon various related aspects of the circulation and metabolism are shown in detail in tables 1, 2, 3, and 4, and in figure 1. They are first discussed separately.

\section{The pulse rate}

The intravenous injection of $1.2 \mathrm{mgm}$. atropine sulphate produced in each subject a prompt rise in the average pulse rate to about 50 per cent (44 to 69 per cent) above its previous level. This effect began to wear off within the first twenty minutes but was not entirely gone after $1 \frac{1}{2}$ hours. In one case observed for 3 hours after the administration of the drug, the rate returned to within 3 beats per minute of the original rate. In several cases during the actual injection there occurred an initial slowing of the rate but in each case the maximum acceleration was obtained within a few minutes after the injection.

\section{The output of the heart}

The control observations agreed well with each other. Following the injection of atropine there occurred an increase in cardiac output of from 8 to 24 per cent in five of the six subjects. In the sixth subject a fall of 17 per cent in the output per minute took place. Since this 
TABLE 1

The effect of injecting atropine upon the pulse rate, respiratory quotient, metabolic rate, excretion of $\mathrm{CO}_{2}$, arterio-venous difference, and cardiac output per minute and per beat

\begin{tabular}{|c|c|c|c|c|c|c|c|}
\hline & $\begin{array}{c}\text { Aver- } \\
\text { age } \\
\text { pulse } \\
\text { rate }\end{array}$ & $\begin{array}{c}\text { Respira- } \\
\text { tory } \\
\text { quo- } \\
\text { tient }\end{array}$ & $\begin{array}{c}\text { Basal } \\
\text { meta- } \\
\text { bolic } \\
\text { rate }\end{array}$ & $\begin{array}{l}\mathrm{CO}_{2} \text { ex- } \\
\text { creted } \\
\text { per } \\
\text { minute }\end{array}$ & $\begin{array}{c}\text { A-V } \\
\text { differ- } \\
\text { ence }\end{array}$ & $\begin{array}{l}\text { Cardiac } \\
\text { output } \\
\text { per } \\
\text { minute }\end{array}$ & $\begin{array}{l}\text { Cardiac } \\
\text { output } \\
\text { per } \\
\text { beat }\end{array}$ \\
\hline & & & per cent & $c c$. & $\begin{array}{l}\text { volumes } \\
\text { per cent }\end{array}$ & $c c$. & $c c$. \\
\hline \multicolumn{8}{|l|}{ Subject 1 (W. G.): } \\
\hline March 17, 8:30 a.m.... & 72 & 0.81 & -14 & 181 & 3.11 & 5,820 & 81 \\
\hline March 18, 9:30 a.m........ & 67 & 0.80 & -15 & 178 & 3.15 & 5,650 & 84 \\
\hline March $18,10: 10$ a.m.*...... & 110 & 0.80 & -12 & $185^{\circ}$ & 2.60 & 7,110 & 65 \\
\hline March 18, 11:20 a.m........ & 85 & 0.83 & -17 & 177 & 2.52 & 7,020 & 83 \\
\hline \multicolumn{8}{|l|}{ Subject 2 (F. N.): } \\
\hline March 24, 8:30 a.m........ & 76 & 0.76 & +2 & 193 & 3.61 & 5,350 & 70 \\
\hline March $25,8: 45$ a.m. ...... & 79 & 0.79 & +0 & 191 & 3.96 & 4,820 & 61 \\
\hline March 25, 9:42 a.m.*.... & 112 & 0.72 & -2 & 179 & 2.84 & 6,300 & 56 \\
\hline March 25, 11:00 a.m........ & 84 & 0.76 & -8 & 174 & 2.88 & 6,040 & 72 \\
\hline \multicolumn{8}{|l|}{ Subject 3 (T. A.): } \\
\hline March 31, 8:30 a.m........ & 65 & 0.81 & -15 & 182 & 4.62 & 3,940 & 60 \\
\hline April $\quad 1,10: 40$ a.m. ${ }^{*} \ldots$ & 93 & 0.78 & -11 & 186 & 3.65 & 5,100 & 55 \\
\hline April $\quad 1,11: 48$ a.m........ & 75 & 0.79 & -14 & 179 & 3.32 & 5,390 & 72 \\
\hline April $10,8: 30$ a.m......... & 62 & 0.89 & -15 & 189 & 4.37 & 4,320 & 70 \\
\hline \multicolumn{8}{|l|}{ Subject 4 (M. H.): } \\
\hline April $14,8: 30$ a.m........ & 64 & 0.83 & -13 & 198 & 5.01 & 3,950 & 62 \\
\hline April $15,8: 15$ a.m........ & 61 & 0.84 & -12 & 203 & 5.02 & 4,040 & 66 \\
\hline April $15,9: 15$ a.m. ${ }^{*} \ldots \ldots$ & 91 & 0.84 & -12 & 199 & 4.62 & 4,300 & 47 \\
\hline April $15,10: 36$ a.m........ & 74 & 0.82 & -14 & 191 & 3.72 & 5,140 & 69 \\
\hline \multicolumn{8}{|l|}{ Subject 5 (C. K.): } \\
\hline April 22, 8:30 a.m...... & 71 & 0.84 & -19 & 177 & 4.10 & 4,320 & 61 \\
\hline April 23, 9:00 a.m...... & 65 & 0.86 & -16 & 185 & 4.74 & 3,900 & 60 \\
\hline April $23,10: 19$ a.m.* $\ldots \ldots$ & 115 & 0.86 & -20 & 176 & 5.15 & 3,420 & 30 \\
\hline April $23,11: 50$ a.m........ & 81 & 0.84 & -25 & 162 & 5.06 & 3,200 & 40 \\
\hline \multicolumn{8}{|l|}{ Subject 6 (C. B.): } \\
\hline May 6, 8:00 a.m.... & 63 & 0.87 & -17 & 173 & 3.73 & 4,650 & 74 \\
\hline May 6, 9:00 a.m.*......... & 104 & 0.76 & -14 & 160 & 2.90 & 5,520 & 53 \\
\hline May $6,10: 20$ a.m........... & 76 & 0.74 & -21 & 144 & 3.27 & 4,400 & 58 \\
\hline May $6,11: 50$ a.m.......... & 66 & 0.77 & -15 & 158 & 3.45 & 4,580 & 69 \\
\hline
\end{tabular}

* 1 to 2 minutes before this time the subject received an intravenous injection of 1.2 mgm. atropine sulphate. Immediately thereafter the determination of the cardiac output was begun. 
method with trained subjects is expected to yield results accurate to about 10 per cent, it is clear that there is usually a slight increase in cardiac output following the administration of atropine. Since the metabolic rate and the production of carbon dioxide were essentially unchanged, it is evident that the difference between the carbon dioxide contents of the arterial and venous blood was diminished (table 1).

The average change in cardiac output per minute was an increase of 14 per cent. Comparison of this with the average increase of 54 per

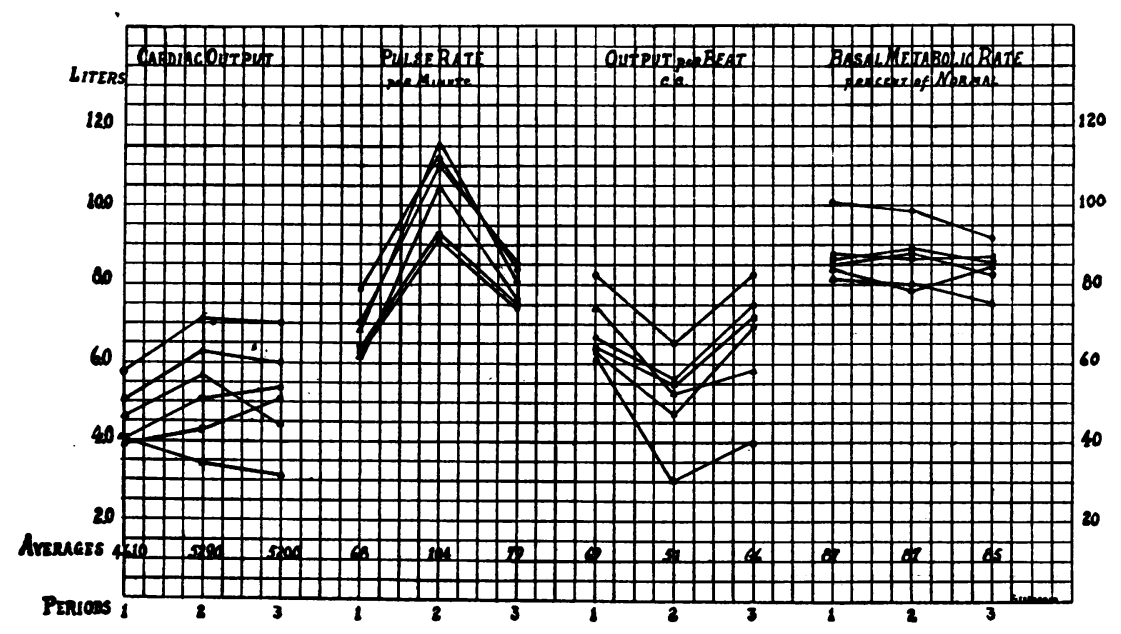

Fig. 1. Graphic Records of the Cardiac Output, Pulse Rate, and Basal Metabolic Rate in Six Subjects

Period 1-before giving atropine; Period 2-immediately afterward; Period $3-1$ to $1 \frac{1}{2}$ hours after injection of atropine.

cent in heart rate implies a marked diminution in the output of the heart per beat. These relations are shown graphically in figure 1.

The cardiac output per minute usually remained slightly above the resting level until the final determinations 1 to $1 \frac{1}{2}$ hours after the administration of the drug. At this time the pulse rate and output per minute were both about 12 per cent above the level existing before injection and the output per beat therefore about the same as in the control observations. 


\section{The metabolic rate}

No constant change in the metabolic rate was observed following the administration of atropine. In fact, the average rates just before and just after injection were identical. As is usual with trained subjects the basal rates are uniformly low. The respiratory minute volume increased on the average 4 per cent, which fits in with the absence of change in metabolic rate.

\section{The blood pressure}

It is realized that figures for the diastolic pressure are not accurate because of the difficulty of recognizing the diastolic point by the usual criteria. This difficulty we attempted to minimize by having all

TABLE 2

Percentage changes in pulse rate and cardiac output per minute and per beat following the injection of $1.2 \mathrm{mgm}$. atropine sulphate intravenously

\begin{tabular}{|c|c|c|c|c|c|c|c|}
\hline & \multicolumn{6}{|c|}{ Subject } & \multirow{2}{*}{$\begin{array}{c}\text { Aver- } \\
\text { age }\end{array}$} \\
\hline & 1 & 2 & 3 & 4 & 5 & 6 & \\
\hline Pulse rate per minute $\ldots \ldots \ldots$ & +57 & +45 & +46 & +45 & +69 & +65 & +56 \\
\hline Cardiac output per minute. .... & +24 & +24 & +23 & +8 & -17 & +19 & +14 \\
\hline Cardiac output per beat. . . . . & -22 & -15 & -15 & -27 & -51 & -28 & -26 \\
\hline
\end{tabular}

pressures taken with the same mercury manometer and by the same observer. Even so, successive observations sometimes showed a striking lack of agreement. Our observations on the effect of atropine on the blood pressure are summarized in tables 3 and 4 .

Table 3 shows the blood pressure reading just before and for some twenty minutes after the administration of the drug, with simultaneous pulse rates. It emphasizes the striking lack of correlation between heart rate and blood pressure in that the former may nearly double without change in the latter. In two instances there was a definite rise in both systolic and diastolic pressures.

Table 4 represents averages of all the pulse pressure figures obtained before and after injecting atropine. No constant change was observed but the average pulse pressures before and after atropine are nearly identical. The systolic pressures before giving atropine vary from 
W. C. SMITH, C. S. BURWELL AND M. J. DE VITO

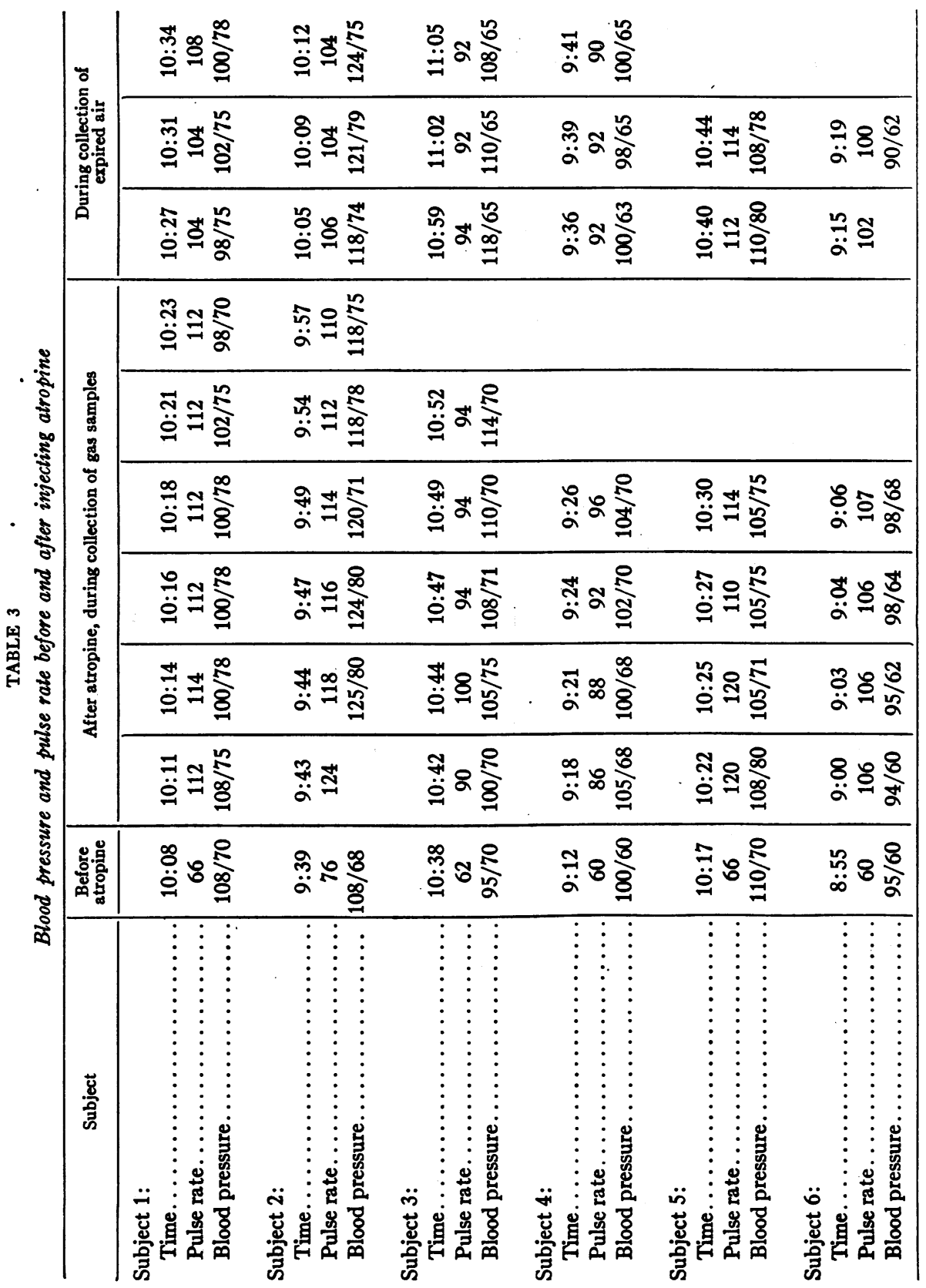


95 to $110 \mathrm{~mm}$. This'range of pressure is that usually found in healthy young men under standard basal conditions.

\section{DISCUSSION}

The administration of atropine, according to these observations, increases the rate of the heart relatively much more than the output of the heart per minute and thus produces a diminution in the output of the heart per beat. This fact emphasizes the importance of the filling of the heart in relation to its output, and thus the importance of the factors determining the venous pressure. These factors include gravity, the aspirating action of the thorax and the contraction of the muscles of the body as well as the pumping force of ventricular systole. Atropine has, of course, effects other than acceleration of the heart.

TABLE 4

Tl.e pulse pressure (in millimeters of mercury) before and after the intravenous injection of 1.2 mgm. atropine sulphate. Each figure represents the average of several measurements

\begin{tabular}{|c|c|c|c|c|c|c|c|}
\hline & \multicolumn{6}{|c|}{ Subject } & \multirow{2}{*}{$\begin{array}{l}\text { Aver- } \\
\text { age }\end{array}$} \\
\hline & 1 & 2 & 3 & 4 & 5 & 6 & \\
\hline Before atropine. .......... & 31 & 38 & 28 & 38 & 35 & 37 & 34.5 \\
\hline Immediately after atropine........ & 25 & 44 & 40 & 34 & 30 & 33 & 34.3 \\
\hline 1 to 2 hours after atropine........ & 30 & 45 & 27 & 28 & 32 & 30 & 32.0 \\
\hline
\end{tabular}

These include according to Cushny (9) a sedative action on many organs containing unstriped muscle, a decrease of most secretions, and a stimulation of the central nervous system, particularly the motor divisions of the brain. These effects, particularly the last, which is presumably responsible for the restlessness sometimes observed in our experiments, may possibly affect the filling of the heart and thus account for the small but definite increase which was observed.

The oxygen consumption of the resting human heart, according to Bainbridge (10) is about $12.5 \mathrm{cc}$. per minute. This amount is approximately 5 per cent of the total oxygen consumption of the body per minute. This being true small changes in the work of the heart can hardly be recognized by changes in the total oxygen consumption. The unchanging metabolic rate in these experiments cannot be taken as evidence that the work of the heart was not increased.

The absence of constant changes in the blood pressure levels indi- 
cates the extraordinary adjustability of a circulatory mechanism which can suffer a large sudden increase in pumping strokes per minute without alteration of pressure. Indeed it appears that heart rate, cardiac output, or blood pressure may change, within limits, without involving each other, so perfect and instant are the compensatory mechanisms. Such compensatory adjustments must be of fundamental importance in the reaction of the circulation to diseases of the heart.

\section{SUMMARY}

Atropine administered intravenously to normal men produces a marked rise in heart rate, a relatively small rise in cardiac output per minute and no change in pulse pressure or metabolic rate.

The acceleration of the heart rate is accompanied by a diminution of the output of the heart per beat.

\section{BIBLIOGRAPHY}

1. Field, H., Jr., and Bock, A. V., J. Clin. Invest., 1925-26, ii, 67. Orthopnea and the Effect of Posture upon the Rate of Blood Flow.

2. Marshall, E. K., Jr., J. Pharm. and Exper. Therap., 1926, xxix, 167. Studies on the Cardiac Output of the Dog. II. The Influence of Atropine and Carbon Dioxide on the Circulation of Unanesthetized Dogs.

3. Harrison, Tinsley Randolph, Blalock, Alfred, Pilcher, Cobb, and Wilson, Chas. P., Am. J. Physiol., 1927, 1xxxiii, 284. The Regulation of the Circulation. VIII. The Relative Importance of Nervous, Endocrine and Vascular Regulation in the Response of the Cardiac Output to Anoxemia.

4. Stewart, Harold J., J. Clin. Invest., 1926-27, iii, 241. The Effect of Increased Heart Rate Due to the Injection of Atropine on the Oxygen Saturation of the Arterial and Venous Blood of Patients with Heart Disease.

5. Harris, I., The Lancet, 1921, i, 1072. The Action of Digitalis and Atropine on the Peripheral Blood Pressure.

6. Sturgis, Cyrus C., Wearn, Joseph T., and Tompkins, Edna H., Am. J. Med. Sci., 1919, clviii, 496. Effects of the Injection of Atropine on the Pulse Rate, Blood Pressure and Basal Metabolism in Cases of "Effort Syndrome."

7. McGuigan, Hugh, J. Am. Med. Ass., 1921, lxxvi, 1338. The Effect of Small Doses of Atropine on the Heart Rate.

8. Field, H., Jr., Bock, A. V., Gildea, E. F., and Lathrop, F. L., J. Clin. Invest., 1925, $i, 65$. The Rate of the Circulation of the Blood in Normal Resting Individuals.

9. Cushny, Arthur R., A Text-book of Pharmacology and Therapeutics. Lea \& Febiger, Philadelphia, 8th ed., 1924.

10. Bainbridge, F. A., Monographs on Physiology, New York, 1923, 2nd edition, 116. The Physiology of Muscular Exercise. 